\title{
Empat Perspektif Citra dan Harapan terhadap Kawasan Kesawan Kota Medan: Konservasi, Pariwisata, Revitalisasi, dan Pengembangan
}

\author{
Meta Vaniessa Tampubolon ${ }^{1}$ dan Hanson E. Kusuma ${ }^{2}$ \\ ${ }^{1}$ Magister Arsitektur, SAPPK, Institut Teknologi Bandung \\ ${ }^{2}$ Kelompok Keahlian Perancangan Arsitektur, SAPPK, Institut Teknologi Bandung \\ metatampubolon07@gmail.com
}

\begin{abstract}
ABSTRAK
Ciri khas dan sejarah yang terdapat di bangunan dan lingkungan dalam kota menciptakan citra terhadap kawasan yang kemudian disebut kawasan bersejarah. Kawasan Kesawan di Kota Medan menjadi salah satu kawasan bersejarah dan identitas kota. Masalah saat ini adalah kepentingan ekonomi, modernisasi, pembangunan kota yang tidak merata, dan hukum yang tidak terlaksana semestinya mengancam keberadaan kawasan dan bangunan bersejarah. Penelitian ini bertujuan mengungkap citra dan harapan terhadap Kawasan Kesawan dari sudut pandang masyarakat Kota Medan, yang dapat digunakan sebagai pijakan dalam menyusun kebijakan dalam menjaga kelestariannya sebagai kawasan bersejarah. Metode yang digunakan dalam penelitian ini adalah mixed methods. Pengumpulan data dilakukan dengan menggunakan kuesioner daring dengan sample non-random - snowball sampling. Data kualitatif dianalisis isi. Data kuantitatif dianalisis dengan analisis faktor dan analisis korelasi multivariat. Dari analisis citra dan harapan terungkap empat perspektif terhadap Kawasan Kesawan. Pertama perspektif konservasi yang mengharapkan agar identitas Chinatown pada Kawasan Kesawan dipertahankan. Ke-dua perspektif pariwisata yang memiliki citra dominan daya tarik wisata Kawasan Kesawan dan harapan Kawasan Kesawan tetap menjadi icon Kota Medan. Ke-tiga perspektif revitalisasi yang memiliki citra Kawasan Kesawan sulit parkir, ramai di siang hari, namun memiliki daya tarik visual, dan berharap Kawasan Kesawan menjadi kawasan yang hidup. Ke-empat perspektif pengembangan yang mengharapkan adanya perbaikan infrastruktur di area Kawasan Kesawan.
\end{abstract}

Kata kunci: citra, harapan, Kesawan, masyarakat, perspektif

\section{ABSTRACT}

Characteristics and history contained in buildings and environments in the city will create an image of the area which was then called as historic area. Kesawan area in Medan City is one of the historical areas and the identity of the city. The current problems are economic interests, modernization, uneven urban development, and improperly enforced laws that threaten the existence of historic areas and buildings. This study aims to reveal the image and expectations of the Kesawan Area from the viewpoint of the people of Medan City, which can be used as a foothold in formulating policies in maintaining its preservation as a historic area. The methods used in this study are mixed methods, namely qualitative and quantitative. The data collection method is done using an online questionnaire with a non-random sample - snowball sampling. Qualitative data analyzed contents. Quantitative data were analyzed by factor analysis and multivariate correlation analysis. From the analysis of images and expectations revealed four perspectives on the Kesawan Area. First, a conservation perspective that hopes that Chinatown's identity in the Kesawan Area is maintained. The two tourism perspectives that have a dominant image of the Kesawan Area tourist attraction and the Kesawan Area hope remain the Medan City icon. The three revitalization perspectives that have the image of the Kesawan Area are difficult to park, crowded during the day, but have a 
visual appeal, and hope that the Kesawan Region becomes a living area. The four development perspectives expect infrastructure improvements in the Kesawan area.

Keywords: community, expectation, image, Kesawan, perspective

\section{Pendahuluan}

Kawasan bersejarah penting sebagai identitas sebuah kota. Nilai dan perjalanan sebuah kota terekam pada kawasan bersejarah. Sejarah tertuang pada bentuk dan karakter bangunan yang ada pada kawasan. Bentuk bangunan ini akan menjadi identitas bagi kawasan. Citra kawasan perlu dipahami oleh masyarakat untuk melihat keberhasilan dari produk rancangan dan kondisi lingkungan bersejarah tersebut (Pettricia, Wardhani, \& Antariksa, 2014). Karakter bentuk dan sejarah yang terdapat pada bangunan menjadi bagian penting terbentuknya citra kawasan bersejarah. Persepsi masyarakat atau gambaran yang ditimbulkan oleh daya tarik suatu kawasan terhadap masyarakat dapat menciptakan sense of place atau citra kawasan (Hadinugroho, 2016). Namun disayangkan keberadaan kawasan dan bangunan bersejarah tergeser oleh beberapa kepentingan seperti ekonomi, modernisasi, pembangunan kota yang tidak merata, dan hukum yang tidak terlaksana sebagaimana mestinya. Peralihan fungsi bangunan tanpa mempertimbangkan sejarah dan arsitektural bangunan, penghancuran bangunan untuk fungsi bangunan yang lain, kurangnya kesadaran masyarakat terhadap sejarah bangunan yang ada atau dimiliki, dilatarbelakangi oleh pertumbuhan penduduk yang tinggi atau kepentingan ekonomi. Hal tersebut menyebabkan penghancuran keutuhan nilai sejarah pada bangunan bersejarah demi memenuhi fungsi bangunan yang lain sesuai kebutuhan pemilik (Rachman, 2012).

Hal lain yang menjadi masalah dalam kawasan bersejarah adalah modernisasi. Perubahan pola aktifitas dahulu dengan sekarang menyebabkan perubahan fungsi ruang dan facade pada bangunan. Kurangnya pengetahuan pemilik akan sejarah yang dimiliki bangunannya memperparah pergeseran nilai sejarah yang ada. Karakter kawasan bersejarah tergeser oleh modernisasi. Modernisasi menyebabkan karakter bangunan dan sejarah kawasan hilang. Kehilangan ini berdampak pada krisis identitas. Pengetahuan sejarah kawasan menjadi hal penting karena kawasan bersejarah memiliki karakter yang beragam dan cara pelestarian yang berbeda di setiap kawasannya (Rahardjo, 2013).

Pembangunan yang tidak merata pada seluruh bagian kota juga berdampak buruk pada kawasan bersejarah. Bangunan bersejarah merupakan bangunan tua dengan utilitas yang membutuhkan perawatan khusus. Pada kenyataannya perawatan untuk utilitas bangunan tua tidak berjalan. Terbengkalainya utilitas bangunan menyebabkan bangunan tidak berfungsi dengan layak (Purwantiasning, 2012). Isu-isu bangunan sejarah ini juga terkait dengan Kawasan Kesawan. Kawasan Kesawan merupakan kawasan bersejarah di Kota Medan. Kawasan Kesawan mengalami beberapa isu terkait dengan hukum yang tidak dilaksanakan semestinya, bersaing dengan modernisasi, masyarakat yang mengutamakan nilai ekonomi ketimbang sejarah di kawasan, dan adanya pembangunan tidak merata di Kota Medan yang menjadikannya kurang diperhatikan (Tampubolon, et al, 2019).

Hadinugroho (2018) juga mengkritik dan mengunkap model proses dan hasil teknik penghilangan yang berlangsung di Kawasan Kesawan adalah pengabaian (neglected), pemotongan/ amputasi atau peniadaan objek, model devitalisas (inactivity) atau peniadaan fungsi, model perubahan arsitektur (redesign) atau tidak kontekstual dengan arsitektur heritage Kesawan, model topengan (masking/facelift) atau peniadaan elemen bersejarah dengan menutup facade tampak arsitektur hampir seluruh bangunan. Seperti yang dikatakan oleh Hadinugroho (2017), banyak perubahan yang terjadi di 
Kawasan Kesawan Medan dengan dalih modernisasi dan kemajuan peradaban. Telah dilakukan beberapa kali penelitian mengenai Kawasan Kesawan di Kota Medan. Lubis (2004) membahas kepraktisan pembangunan bangunan ruko yang berdampak mengaburkan identitas Kawasan Kesawan. Kepraktisan membangun merupakan perkembangan peradaban yang tidak dapat dihindarkan, namun harus dibarengi dengan aturan yang jelas seperti yang pada UU No.11 tahun 2010. Cara merevitalisasi dan mengembalikan citra Kawasan Kesawan telah diteliti oleh Hadinugroho (2017) yang mengidentifikasi dan menggali potensi Kawasan Kesawan. Fatimah (2017) meneliti tentang rencana lanskap Kawasan Kesawan. Penelitian ini menghasilkan kriteria perancangan. Penelitian-penelitian tersebut dapat dikolaborasikan dengan penelitian dengan kasus serupa oleh Tutuko (2010) yang membahas mengenai konsep konservasi untuk bangunan tua untuk difungsikan kembali pada daerah pecinan di Singapura.

Berbeda dengan penelitian-penelitian sebelumnya yang dimulai dari sudut pandang objek yaitu Kawasan Kesawan, penelitian ini bergerak dari sudut pandang pengguna dan pengamat yaitu masyarakat Kota Medan. Penelitian mengenai citra Kawasan Kesawan dari sudut pandang masyarakat telah dilakukan sebelumnya namun sangat dipengaruhi interpretasi oleh peneliti. Penelitian sejenis dilakukan kembali dengan lebih ditegaskan oleh responden. Sudut pandang masyarakat dipilih karena citra kawasan tidak terlepas dari aktifitas dan perilaku pengguna yaitu masyarakat. Masyarakat yang telah mengalami banyak aktifitas dan mengamati kawasan akan meciptakan penilaian terhadap citra dan menumbuhkan harapan terhadap kawasan kedepannya. Harapan yang dihasilkan merupakan kebutuhan dari masyarakat. Proses realisasi dari harapan akan lebih mudah karena merupakan kebutuhan yang dirasakan oleh masyarakat.

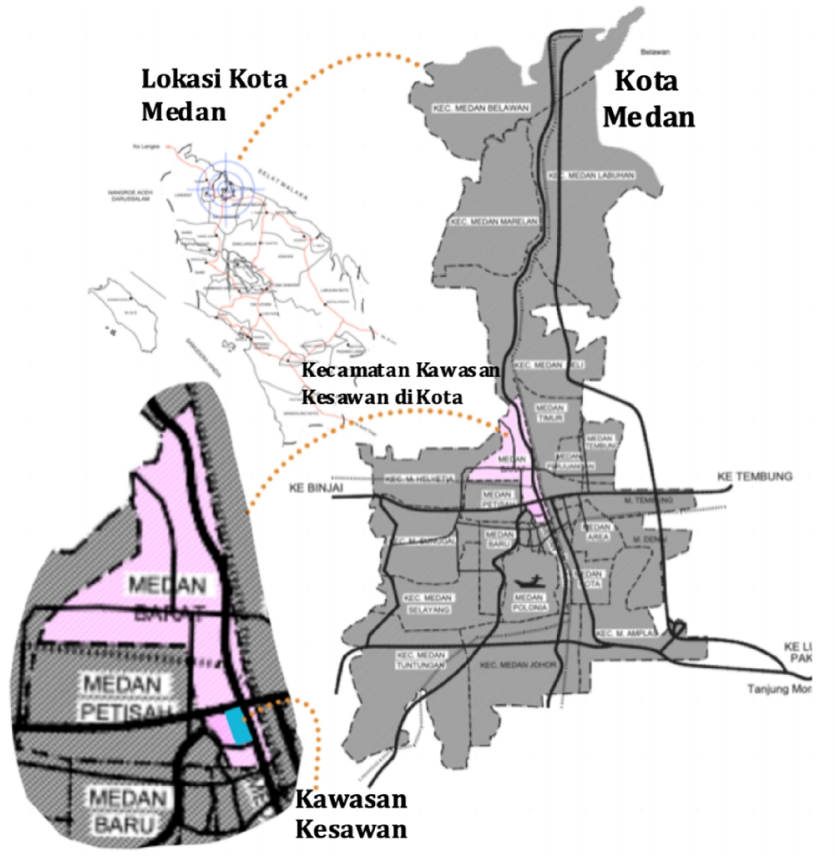

Gambar 1. Peta Lokasi Kawasan Kesawan

(Sumber: Tampubolon \& Kusuma, 2020)

Penelitian ini bertujuan untuk menemukan citra dan harapan terhadap Kawasan Kesawan dari sudut pandang masyarakat di Kota Medan berdasarkan korelasi antara keduanya. Penelitian ini diharapkan dapat memberi informasi yang bermanfaat kepada perencana, arsitek, dan pemerintah agar proses perencanaan revitalisasi dapat didukung oleh masyarakat dan dapat direalisasikan. Penelitian ini juga diharapkan dapat bermanfaat 
bagi akademisi dengan mengungkap wawasan baru tentang citra dan harapan terhadap Kawasan Kesawan di Kota Medan di mata masyarakat.

\section{Bahan dan Metode}

Metode yang digunakan dalam penelitian ini adalah mixed methods yaitu kualitatif dan kuantitatif. Penelitian tahap pertama menggunakan metode kualitatif Grounded Theory (Creswell, 2006) dan penelitian tahap ke-dua menggunakan metode kuantitatif Correlational Research (Groat \& Wang, 2002). Penelitian tahap pertama bertujuan untuk mengumpulkan citra dan harapan yang berasal dari pemahaman responden. Penelitian tahap ke-dua bertujuan menemukan dimensi-dimensi dari citra dan harapan terhadap Kawasan Kesawan, serta hubungan korelasional antara citra dan harapan tersebut.

\section{Metode Pengumpulan Data}

Pengumpulan daya pada penelitian ini dibagi menjadi pengumpulan data primer menggunakan metode survey dalam bentuk kuesioner daring (online) yang dilakukan peneliti (Kumar, 2005). Kuesioner daring disebar pada bulan September tahun 2018, cara ini dipilih untuk mempermudah peneliti mengakses masyarakat yang berada di berbagai daerah sehingga efektif dan efisien dari segi waktu.

\section{Tahap Pertama}

Metode pengumpulan data dilakukan dengan menggunakan kuesioner daring yang disebarkan kepada masyarakat yang pernah atau tinggal di Kota Medan (non-randomsnowball sampling). Pertanyaan yang diberikan kepada responden bersifat terbuka (openended) dengan dua pertanyaan tentang persepsi masyarakat Kota Medan mengenai citra dan harapan terhadap Kawasan Kesawan. Pertanyaan terbuka tersebut seperti berikut:

"Bagaimanakah kesan anda terhadap Kawasan Kesawan? Jelaskan selengkap mungkin."

"Bagaimana keadaan yang anda harapkan terhadap Kawasan Kesawan di Kota Medan? Deskripsikan dengan detail Kawasan Kesawan seperti apa yang anda inginkan untuk waktu ke depan."

Tabel 1. Kategori Responden

\begin{tabular}{|c|c|c|c|c|c|c|l|l|l|}
\hline & \multicolumn{2}{|c|}{ Jenis Kelamin } & \multicolumn{3}{|c|}{ Usia } & \multicolumn{2}{|c|}{ Bekerja } & \multicolumn{2}{|c|}{ Mahasiwa } \\
\cline { 2 - 9 } & Laki-laki & Perempuan & $\begin{array}{c}12-25 \\
\text { (Remaja) }\end{array}$ & $\begin{array}{c}26-45 \\
\text { (Dewasa) }\end{array}$ & $\begin{array}{c}46-65 \\
\text { (Lansia) }\end{array}$ & $\begin{array}{l}\text { Bidang } \\
\text { Arsitektu } \\
\text { r/PWK }\end{array}$ & $\begin{array}{l}\text { Di luar } \\
\text { Bidang } \\
\text { Arsitekt } \\
\text { ur/PWK }\end{array}$ & $\begin{array}{l}\text { Bidang } \\
\text { Arsitektur/ } / \text { PWK } \\
\text { PWh }\end{array}$ & $\begin{array}{l}\text { Di luar } \\
\text { Bidang } \\
\text { Arsitektur/ } \\
\text { PWK }\end{array}$ \\
\cline { 2 - 9 } & 99 & 75 & 99 & 67 & 8 & 30 & 78 & 28 & 38 \\
\hline
\end{tabular}

(Sumber: Hasil Analisis, 2018)

Dari tahap pertama diperoleh data dari 174 responden dengan usia 18-54 tahun. Semua responden pernah atau tinggal di Kota Medan dengan pekerjaan berada dalam dan luar bidang arsitektur atau perencanaan wilayah dan kota seperti yang dijelaskan pada tabel 1. Jawaban dari responden berupa data teks yang kemudian dianalisis dengan analisis isi. Analisis isi menggunakan open coding, axial coding, dan selective coding. Open coding digunakan untuk mengidentifikasi kata kunci dan mengkategorikan kata-kata kunci yang mirip. Axial coding digunakan untuk melihat hubungan antar kategori. Selective coding digunakan untuk menyusun hipotesis. Salah satu kategori dan kata kunci pada tahap open coding seperti berikut: 


$$
\begin{aligned}
& \text { Kategori : "Kurang Nyaman" berasal dari } \\
& \text { Kata kunci : "Gelap”, “Menyeramkan”, "Sepi”, "Tidak Ramah Difabel” } \\
& \text { Kategori : "Mempertahankan Bangunan Lama" berasal dari } \\
& \text { Kata kunci : "Diperbaiki”, "Dipertahankan”, "Tidak Dirusak/ } \\
& \text { Dihancurkan", "Tidak Merubah Bangunan Lama" }
\end{aligned}
$$

Pada axial coding hubungan antar kategori diungkap dengan analisis korespondensi menggunakan aplikasi JMP. Dari analisis korespondensi ditemukan korespondensi antara citra dan harapan memiliki nilai signifikansi sebesar $p=0.5695$, yang menunjukkan citra dan harapan memiliki hubungan yang kurang signifikan. Dan hasil analisis korespondensi, hubungan citra dan harapan Kawasan Kesawan dapat dibagi menjadi enam, yaitu:

1. Terlupakan, dan diharapkan dapat berperan di masyarakat.

2. Tidak terencana, kehilangan citra, namun menarik, dan diharapkan dapat dapat ditata kembali.

3. Macet, dan diharapkan menjadi area khusus pejalan kaki.

4. Berharga dan diharapkan dapat mempertahankan citranya.

5. Kawasan bersejarah yang diharapkan dapat menarik wisatawan.

6. Menjaga keamanan kawasan.

\section{Tahap Kedua}

Variabel atau kata kunci yang berasal dari penelitian kualitatif tahap pertama kemudian digunakan pada penelitian tahap ke-dua dengan pendekatan kuantitatif. Pengumpulan data yang dilakukan juga menggunakan kuesioner daring dengan pertanyaan bersifat tertutup (close-ended). Metode sampling yang dilakukan adalah nonrandom sampling, yaitu snowball sampling. Kuesioner dibagikan pada bulan Agustus tahun 2019 dengan target responden yang pernah atau tinggal di Kota Medan. Sebagian responden yang mengisi kuesioner tahap dua berbeda dengan responden pada tahap satu. Jumlah responden yang diperoleh pada tahap ini sebanyak 124. Proporsi pekerjaan responden yang bekerja di dalam bidang arsitektur atau perencanaan wilayah dan kota sebanyak 54\% (67 orang) dan di luar bidang arsitektur atau perencanaan wilayah dan kota sebanyak 46\% (57 orang).

Pertanyaan tertutup yang ditanyakan kepada responden disusun menggunakan jawaban dengan Skala Likert. Jawaban yang diberikan akan mempresentasikan tingkatan kesetujuan responden terhadap citra dan harapan Kawasan Kesawan. Setiap pertanyaan memiliki skala jawaban dengan skala 1 sampai 5. Skala tersebut memiliki dua sisi yang berlawanan. Skala 1 menunjukkan sangat tidak setuju, sedangkan skala 5 menunjukkan sangat setuju.

Metode analisis yang digunakan pada penelitian ini adalah analisis komponen prinsip, analisis faktor, dan analisis korelasi multivariat. Analisis komponen prinsip digunakan untuk mengidentifikasi komponen prinsip yang memiliki varians lebih besar dan dapat mewakili variabel terukur (Bryant \& Yarnold, 2001). Selanjutnya komponen prinsip yang diperoleh dirotasi menggunakan varimax rotations pada analisis faktor. Hasil analisis faktor berupa variabel laten/dimensi yang independen satu sama lain. Analisis terakhir adalah analisis korelasi multivariat untuk menemukan hubungan korelasional antar dimensi citra dan harapan.

\section{Hasil Dan Pembahasan}

\section{Citra Kawasan Kesawan}

Data citra Kawasan Kesawan diperoleh dari 44 pertanyaan. Contoh pertanyaan dapat dilihat pada tabel 2. Nama variabel dari 44 pertanyaan dapat dilihat pada tabel 3. 
Tabel 2. Contoh Pertanyaan Citra

\begin{tabular}{|c|c|c|c|c|c|c|c|}
\hline Kategori & \multicolumn{7}{|c|}{ Contoh Pertanyaan } \\
\hline \multirow{8}{*}{$\begin{array}{l}\text { Citra } \\
\text { Kawasan } \\
\text { Kesawan }\end{array}$} & \multicolumn{7}{|c|}{ Kebudayaan yang ada di Kawasan Kesawan Beragam } \\
\hline & Sangat Tidak Setuju & 1 & 2 & 3 & 4 & 5 & Sangat Setuju \\
\hline & \multicolumn{7}{|c|}{$\begin{array}{l}\text { Struktur bangunan lama yang masih ada di Kawasan Kesawan sampai saat ini masil } \\
\text { terlihat kokoh. }\end{array}$} \\
\hline & Sangat Tidak Setuju & 1 & 2 & 3 & 4 & 5 & Sangat Setuju \\
\hline & \multicolumn{7}{|c|}{ Jalur pejalan kaki dan fasilitas di Kawasan Kesawan tidak ramah untuk difabel } \\
\hline & Sangat Tidak Setuju & 1 & 2 & 3 & 4 & 5 & Sangat Setuju \\
\hline & \multirow{2}{*}{\multicolumn{7}{|c|}{ Jalan raya di Kawasan Kesawan ramai saat siang hari. }} \\
\hline & & 1 & 2 & 3 & 4 & 5 & Sangat Setuju \\
\hline
\end{tabular}

(Sumber: Hasil Analisis, 2018)

Dari analisis faktor terhadap 44 variabel terukur tentang citra Kawasan Kesawan, diperoleh 13 variabel laten/dimensi seperti yang diperlihatkan pada tabel 3. Dari 13 variabel laten terdapat enam variabel citra yang baik dan tujuh variabel citra kawasan yang buruk. Enam citra yang baik dari variabel laten, yaitu: kawasan konservasi, daya tarik wisata, identitas, budaya, daya tarik visual, dan kawasan Chinatown. Tujuh citra yang buruk dari variabel laten, yaitu: seram, lingkungan kotor, jalur pedestrian buruk, keramaian siang, sulit parkir, keramaian malam, dan aksesibilitas sulit.

\section{Tabel 3. Faktor Analisis Citra Kawasan Kesawan}

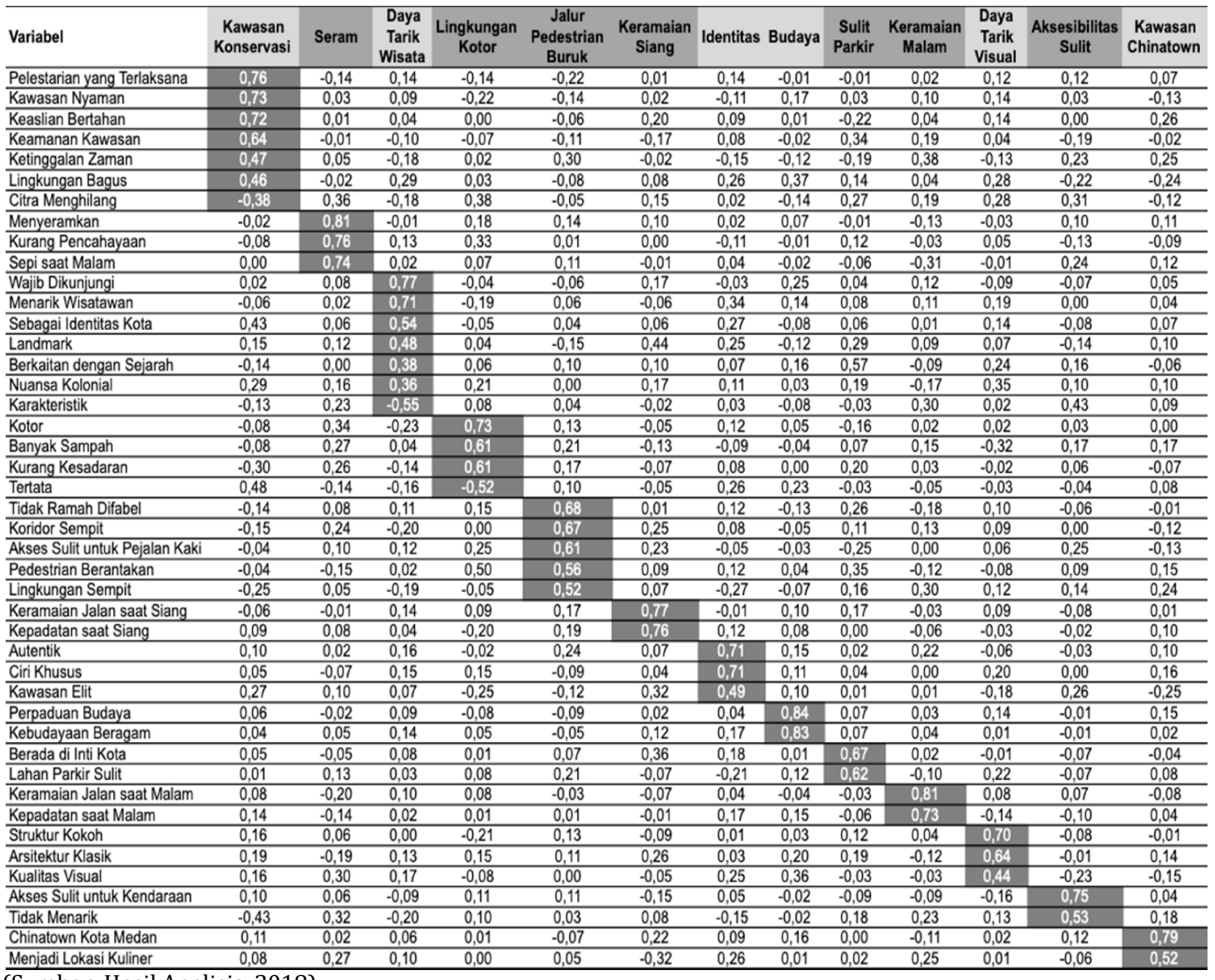

(Sumber: Hasil Analisis, 2018) 
Kawasan konservasi, tersusun dari empat variabel terukur tentang citra yang memiliki factor loading di atas 0,5, yaitu: pelestarian yang terlaksana, kawasan nyaman, keaslian bertahan, dan keamanan kawasan. Penamaan variabel laten kawasan konservasi berasal dari pelestarian yang merupakan tindakan pada Kawasan Kesawan. Adanya tindakan pelestarian membentuk citra kawasan yang nyaman, keaslian yang bertahan, kawasan menjadi aman, dan lingkungan menjadi bagus sebagai kawasan konservasi. Hal ini menjadikan citra kawasan bertahan.

Daya tarik wisata, yang berasal dari tiga variabel terukur citra (factor loading di atas 0,5) yang menyatakan bahwa citra Kawasan Kesawan wajib untuk dikunjungi, menarik untuk wisatawan, dan dapat dijadikan sebagai identitas Kota Medan. Identitas, didukung dengan variabel terukur dominan yang berkaitan dengan kawasan yang autentik dan memiliki ciri khusus. Budaya, sesuai dengan kedua variabel terukur yang berkaitan dengan perpaduan budaya yang ada dalam citra Kawasan Kesawan. Bagi masyarakat Kota Medan, Kawasan Kesawan dianggap memiliki kebudayaan yang beragam dan terasa memiliki perpaduan budaya bagi masyarakat.

Variabel laten ke-lima yang dihasilkan dari analisis faktor citra yang baik Kawasan Kesawan yaitu daya tarik visual. Daya tarik visual mewakili variabel terukur yang berkaitan dengan bangunan pada Kawasan Kesawan yang dilihat oleh masyarakat. Bangunan lama dengan struktur yang masih terlihat kokoh, terlihat gaya arsitektur klasik pada beberapa bangunan di Kawasan Kesawan, menghasilkan kualitas visual kawasan yang indah untuk dinikmati.

Kawasan Chinatown sebagai penamaan variabel laten citra kawasan baik yang terakhir. Fungsi sebagai area kuliner Kota Medan dahulu di Kawasan Kesawan sampai sekarang masih melekat. Sejarah kawasan pecinan dari tahun 1900 pada kawasan ini menyematkan identitas Chinatown Kota Medan untuk Kawasan Kesawan.

Variabel laten citra buruk yang pertama dari Kawasan Kesawan, yaitu lingkungan kotor. Responden melihat Kawasan Kesawan memiliki banyak sampah, kotor, dan kurang adanya kesadaran dari pemilik mengenai koridor pedestrian yang berantakan. Citra lingkungan Kawasan Kesawan juga dianggap kurang tertata bagi responden.

Citra buruk yang ke-dua jalur pedestrian buruk yang mewakili variabel terukur pedestrian yang tidak ramah difabel, koridor pedestrian yang sempit dan tidak bebas hambatan menyulitkan pejalan kaki untuk berjalan di sepanjang kawasan. Pedestrian dinilai responden berantakan dengan adanya barang dagangan para pemilik ruko, tiang listrik, dan beberapa pot bunga di area pedestrian.

Keramaian siang citra buruk yang ada di Kawasan Kesawan tidak terlepas dari keramaian kawasan di siang hari. Area kawasan padat masyarakat pada siang hari. Citra buruk kawasan selanjutnya yang menjadi variabel laten sulit parkir. Keberadaan Kawasan Kesawan di inti Kota Medan menjadikannya lokasi yang sulit untuk parkir.

Keramaian malam dirasakan oleh responden di Kawasan Kesawan. Citra ramai di Kawasan Kesawan dirasakan baik siang maupun malam. Banyak masyarakat yang beraktifitas di area kawasan ini. Variabel laten mengenai citra buruk Kawasan Kesawan yang terakhir yaitu aksesibilitas sulit. Kendaraan yang ingin melewati kawasan ini sering terhambat dan sulit untuk melaluinya. Keadaan ini menjadikan Kawasan Kesawan kehilangan pengunjung karena sulit untuk diakses.

\section{Harapan terhadap Kawasan Kesawan}

Data harapan terhadap Kawasan Kesawan diperoleh dari 40 pertanyaan. Contoh pertanyaan dapat dilihat pada tabel 4 . Nama variabel dari 40 pertanyaan dapat dilihat pada tabel 5. Dari analisis faktor 40 variabel terukur harapan, diperoleh sepuluh variabel laten, yaitu: revitalisasi, infrastruktur, aksesibilitas, fasilitas, identitas Chinatown, konservasi, 
komodifikasi, perluasan, pembatasan akses, dan icon Kota Medan. Ke-sepuluh variabel laten dapat dilihat pada tabel 5.

\section{Tabel 4. Contoh Pertanyaan Harapan}

\begin{tabular}{|c|c|c|c|c|c|c|}
\hline Kategori & \multicolumn{6}{|c|}{ Contoh Pertanyaan } \\
\hline \multirow{8}{*}{$\begin{array}{l}\text { Harapan } \\
\text { terhadap } \\
\text { Kawasan } \\
\text { Kesawan }\end{array}$} & \multicolumn{6}{|c|}{$\begin{array}{l}\text { Diperlengkap dengan rambu yang jelas di setiap area Kawasan Kesawan, seperti: } \\
\text { penunjuk arah. }\end{array}$} \\
\hline & Sangat Tidak Setuju & 2 & 3 & 4 & 5 & Sangat Setuju \\
\hline & \multicolumn{6}{|c|}{$\begin{array}{l}\text { Kawasan Kesawan dijadikan sebagai area yang melekat dan memberi manfaat bagi } \\
\text { lingkungan masyarakat }\end{array}$} \\
\hline & Sangat Tidak Setuju & 2 & 3 & 4 & 5 & Sangat Setuju \\
\hline & \multicolumn{6}{|c|}{$\begin{array}{l}\text { Menyediakan fasilitas yang memadai di dalam Kawasan Kesawan, seperti: tempat } \\
\text { beristirahat, toilet umum, dan fasilitas pendukung lainnya. }\end{array}$} \\
\hline & Sangat Tidak Setuju & 2 & 3 & 4 & 5 & Sangat Setuju \\
\hline & \multicolumn{6}{|c|}{ Menyediakan area kreatifitas untuk anak muda menuangkan seni dan ide kreatif. } \\
\hline & Sangat Tidak Setuju & 2 & 3 & 4 & 5 & Sangat Setuju \\
\hline
\end{tabular}

Tabel 5. Faktor Analisis Harapan terhadap Kawasan Kesawan

\begin{tabular}{|c|c|c|c|c|c|c|c|c|c|c|}
\hline Variabel & Revitalisasi & Infrastruktur & Aksesibilitas & Fasilitas & $\begin{array}{l}\text { Identitas } \\
\text { Chinatown }\end{array}$ & Konservasi & Komodifikasi & Perluasan & $\begin{array}{l}\text { Pembatasan } \\
\text { Akses }\end{array}$ & Tengaran \\
\hline Pedestrian Bebas Hambatan & 0,83 & 0,05 & $-0,03$ & 0,01 & 0,00 & 0,02 & 0,02 & $-0,06$ & 0,14 & $-0,03$ \\
\hline $\begin{array}{l}\text { Mendesain Pedestrian } \\
\text { Ramah Difabel }\end{array}$ & 0,83 & $-0,02$ & 0,09 & 0,14 & 0,03 & $-0,01$ & $-0,05$ & 0,00 & $-0,13$ & 0,16 \\
\hline Menjadi Aset Bersejarah & 0,82 & 0,05 & 0,13 & 0,01 & 0,02 & 0,14 & $-0,16$ & 0,07 & 0,02 & 0,20 \\
\hline $\begin{array}{l}\text { Melestarikan Komponen } \\
\text { Bersejarah }\end{array}$ & 0,82 & 0,09 & 0,03 & $-0,06$ & 0,09 & 0,03 & $-0,15$ & $-0,01$ & $-0,06$ & 0,17 \\
\hline Memperbaiki Drainase & $\overline{0,80}$ & 0,16 & 0,04 & 0,26 & 0,02 & $-0,12$ & $-0,06$ & $-0,05$ & 0,07 & $-0,09$ \\
\hline Meningkatkan Kualitas Visual & 0,80 & $-0,05$ & 0,14 & 0,00 & 0,12 & 0,27 & 0,06 & 0,08 & 0,00 & 0,07 \\
\hline $\begin{array}{l}\text { Seluruh Pedestrian } \\
\text { Terhubung }\end{array}$ & 0,79 & 0,05 & $-0,04$ & 0,29 & 0,01 & $-0,11$ & 0,02 & 0,05 & 0,08 & $-0,02$ \\
\hline Menertibkan Papan Reklame & $\overline{0,76}$ & 0,12 & 0,01 & 0,07 & 0,17 & 0,06 & $-0,08$ & $-0,18$ & 0,01 & 0,07 \\
\hline $\begin{array}{l}\text { Menghidupkan Kawasan } \\
\text { dengan Pencahayaan }\end{array}$ & 0,75 & 0,14 & 0,05 & 0,16 & 0,21 & 0,19 & $-0,13$ & 0,00 & $-0,08$ & 0,14 \\
\hline Bebas dari Sampah & $\overline{0,72}$ & $-0,04$ & 0,26 & 0,08 & 0,10 & 0,27 & 0,01 & 0,23 & $-0,01$ & $-0,01$ \\
\hline Dijaga Pihak Kepolisian & 0,69 & 0,06 & 0,03 & $-0,05$ & $-0,09$ & 0,29 & 0,06 & 0,27 & $-0,13$ & 0,09 \\
\hline $\begin{array}{l}\text { Kondisi Bangunan } \\
\text { Diperhatikan }\end{array}$ & 0,68 & 0,18 & 0,02 & 0,17 & 0,21 & 0,20 & $-0,16$ & 0,02 & 0,00 & 0,00 \\
\hline Zonasi Diperjelas & 0,62 & 0,06 & 0,23 & 0,17 & 0,20 & 0,20 & 0,04 & 0,27 & 0,17 & $-0,21$ \\
\hline $\begin{array}{l}\text { Memperbaiki Bangunan } \\
\text { Kosong }\end{array}$ & 0,62 & 0,06 & 0,12 & 0,24 & 0,09 & 0,25 & $-0,16$ & 0,14 & $-0,17$ & 0,26 \\
\hline Semakin Dikenal & 0,61 & 0,05 & 0,04 & 0,24 & 0,12 & 0,32 & $-0,11$ & 0,19 & $-0,10$ & 0,35 \\
\hline $\begin{array}{l}\text { Menghidupkan Kawasan } \\
\text { dengan Event }\end{array}$ & 0,55 & 0,33 & 0,06 & $-0,23$ & $-0,03$ & 0,23 & $-0,01$ & 0,14 & 0,34 & 0,12 \\
\hline Membuat Penzoningan & $\overline{0,51}$ & 0,04 & 0,06 & 0,15 & 0,49 & 0,17 & 0,11 & 0,23 & 0,15 & $-0,05$ \\
\hline $\begin{array}{l}\text { Mengkontekstualkan Seluruh } \\
\text { Bangunan }\end{array}$ & 0,40 & 0,04 & 0,01 & $-0,09$ & 0,34 & $-0,28$ & $-0,07$ & 0,22 & 0,16 & 0,38 \\
\hline Memperlebar Jalan & $-0,01$ & 0,78 & $-0,03$ & 0,05 & $-0,07$ & 0,03 & 0,16 & 0,35 & $-0,15$ & $-0,13$ \\
\hline Sebagai Lokasi Event & 0,13 & $\overline{0,69}$ & 0,19 & 0,05 & 0,05 & 0,01 & 0,06 & 0,08 & 0,25 & 0,28 \\
\hline Parkir di Dalam Kawasan & 0,09 & 0,61 & 0,04 & 0,18 & 0,25 & 0,07 & 0,20 & 0,15 & $-0,34$ & $-0,12$ \\
\hline Area Kreatifitas & 0,21 & 0,55 & 0,20 & 0,43 & 0,14 & 0,18 & 0,00 & $-0,13$ & 0,01 & 0,06 \\
\hline Mencari Studi Preseden & 0,18 & 0,37 & 0,18 & $-0,06$ & 0,36 & 0,33 & $-0,15$ & $-0,02$ & 0,21 & 0,00 \\
\hline Memberi Rambu & 0,12 & 0,22 & 0,85 & $-0,01$ & 0,11 & 0,05 & $-0,03$ & $-0,05$ & $-0,01$ & $-0,06$ \\
\hline Mempermudah Mobilisasi & 0,16 & 0,01 & 0,76 & 0,11 & 0,04 & 0,13 & 0,12 & $-0,19$ & $-0,12$ & $-0,02$ \\
\hline Memperlancar Jalan & $-0,02$ & $-0,01$ & 0,70 & 0,25 & $-0,02$ & $-0,21$ & $-0,02$ & 0,26 & 0,24 & 0,03 \\
\hline Melekat di Masyarakat & 0,21 & 0,43 & 0,44 & 0,19 & $-0,04$ & 0,23 & $-0,03$ & $-0,15$ & $-0,03$ & 0,32 \\
\hline Parkir di Luar Kawasan & 0,24 & 0,05 & 0,11 & 0,75 & $-0,13$ & 0,23 & 0,04 & 0,00 & 0,12 & 0,13 \\
\hline Melengkapi Fasilitas & 0,40 & 0,30 & 0,23 & 0,69 & 0,07 & $-0,03$ & $-0,08$ & 0,07 & $-0,02$ & 0,06 \\
\hline Memberi Vegetasi & 0,11 & 0,12 & 0,11 & 0,50 & 0,43 & 0,01 & $-0,09$ & 0,34 & 0,08 & $-0,24$ \\
\hline Menjadi Chinatown Medan & 0,16 & 0,02 & 0,00 & 0,00 & 0,83 & $-0,05$ & 0,01 & 0,02 & $-0,01$ & 0,10 \\
\hline $\begin{array}{l}\text { Mengembalikan Fungsi } \\
\text { Kulineran }\end{array}$ & 0,09 & 0,18 & 0,14 & $-0,06$ & 0,56 & 0,10 & 0,46 & $-0,04$ & 0,03 & 0,28 \\
\hline Tidak Dirobohkan & 0,36 & 0,10 & $-0,09$ & 0,09 & $-0,01$ & 0,73 & 0,05 & 0,07 & 0,11 & 0,00 \\
\hline Sebagai Objek Wisata & 0,36 & 0,14 & 0,25 & 0,16 & 0,05 & 0,49 & $-0,16$ & $-0,07$ & $-0,10$ & 0,11 \\
\hline $\begin{array}{l}\text { Mempertahankan Keaslian } \\
\text { Bentuk }\end{array}$ & 0,16 & 0,09 & 0,10 & 0,24 & 0,06 & 0,43 & $-0,49$ & 0,20 & 0,32 & 0,16 \\
\hline Membangun Mall & $-0,18$ & 0,19 & $-0,10$ & 0,03 & 0,01 & $-0,04$ & 0,75 & $-0,04$ & 0,23 & $-0,12$ \\
\hline Modernisasi Kawasan & $-0,15$ & 0,07 & 0,20 & $-0,01$ & 0,09 & 0,01 & 0,62 & 0,18 & $-0,17$ & 0,27 \\
\hline Perluas Kawasan & 0,19 & 0,32 & $-0,15$ & 0,07 & 0,10 & 0,06 & 0,03 & 0,78 & 0,01 & 0,05 \\
\hline Pembatasan Akses & $-0,06$ & $-0,05$ & 0,00 & 0,11 & 0,08 & 0,05 & 0,04 & 0,00 & 0,80 & $-0,01$ \\
\hline Icon Kota Medan & 0,39 & 0,04 & $-0,09$ & 0,10 & 0,16 & 0,10 & 0,11 & $-0,03$ & 0,02 & 0,63 \\
\hline
\end{tabular}

(Sumber: Hasil Analisis, 2018) 
Revitalisasi, merepresentasikan harapan mengenai pedestrian yang bebas hambatan, menghubungkan seluruh pedestrian hingga ke ujung kawasan, desain pedestrian yang ramah difabel, untuk menjadikan Kawasan Kesawan sebagai aset bersejarah, mengadakan upaya perbaikan drainase, meningkatkan kualitas visual kawasan, menertibkan papan reklame di kawasan, menghidupkan kembali kawasan dengan memberi pencahayaan, kawasan juga diharapkan bebas dari sampah, dan adanya upaya untuk memperbaiki bangunan kosong, juga memperhatikan kondisi bangunan, juga membuat penzoningan.

Infrastruktur, merupakan variabel laten tentang harapan terhadap Kawasan Kesawan agar dapat memiliki jalan raya yang lebih lebar, menjadi lokasi event, memiliki lokasi parkir di dalam kawasan, dan mengadakan area kreatifitas untuk melengkapi area kawasan. Variabel laten aksesibilitas, mewakili harapan responden Kawasan Kesawan untuk lebih mudah dijangkau. Variabel laten ini berasal dari gabungan variabel terukur pemberian rambu yang jelas di kawasan, mempermudah mobilisasi kendaraan yang akan singgah di area kawasan dan jalan diharapkan lebih lancar dari yang sekarang, serta akses yang lebih mudah. Variabel laten fasilitas berkaitan dengan harapan untuk perbaikan fasilitas di Kawasan Kesawan. Responden berharap fasilitas parkir di luar kawasan tersedia, fasilitas seperti tempat duduk dan toilet umum di area Kawasan Kesawan dilengkapi, dan vegetasi di area kawasan ditambah dan dirawat. Variabel laten identitas Chinatown pada Kawasan Kesawan mewakili harapan sejarah pecinan yang telah ada sejak dahulu dipelihara dan fungsi area kuliner di dalam Kawasan Kesawan dikembalikan.

Kawasan Kesawan juga diharapkan untuk tetap mempertahankan bangunannya tanpa harus dirobohkan, dijadikan objek wisata, juga tetap mempertahankan keaslian bentuk. Harapan-harapan diwakili dalam satu variabel laten konservasi Kawasan Kesawan. Harapan terhadap Kawasan Kesawan juga berkaitan dengan adanya perbaikan dengan tambahan unsur modernisasi dengan pembangunan mall di area kawasan. Kategori ini berkaitan dengan variabel laten komodifikasi. Kawasan Kesawan juga diharapkan untuk diperluas, yang diwakili variabel laten perluasan. Kendaraan diharapkan untuk tidak bebas melalui Kawasan Kesawan. Responden mengharapkan adanya aturan untuk pembatasan akses kendaraan di Kawasan Kesawan yang menjadi nama variabel laten harapan berikutnya pembatasan akses. Responden juga mengharapkan Kawasan Kesawan untuk menjadi icon Kota Medan yang menjadi nama variabel laten harapan yang terakhir yaitu icon Kota Medan.

\section{Korelasi antara Citra dan Harapan}

Setelah dimensi-dimensi citra dan harapan diketahui, selanjutnya dilakukan analisis korelasi dari kedua kelompok dimensi tersebut, Koefisien korelasi semakin tinggi menunjukkan korelasi antara dua variabel semakin besar. Hasil analisis korelasi menunjukkan empat korelasi yang signifikan.

Empat korelasi dominan antara citra dan harapan diperlihatkan pada tabel 6 . Masing-masing korelasi citra dan harapan tersebut merupakan perwujudan perspektif dari pengguna dan pengunjung Kawasan Kesawan. Karena itu, masing-masing korelasi citra dan harapan dapat diwakili oleh empat perspektif, yaitu: konservasi, pariwisata, revitalisasi, dan pengembangan.

Yang pertama perspektif konservasi, oleh Issemiarti (2011) menyatakan bahwa semaksimal mungkin secara utuh yang mewakili responden yang menilai citra Kawasan Kesawan sebagai Chinatown Kota Medan mengharapkan agar identitas Chinatown pada Kawasan Kesawan tetap dan tidak menghilang. Yang ke-dua perspektif pariwisata, responden yang menilai citra Kawasan Kesawan seram namun memiliki daya tarik wisata memiliki harapan untuk Kawasan Kesawan dijadikan tengaran dan menjadi pusat kegiatan. Yang ke-tiga perspektif revitalisasi, responden yang menilai citra Kawasan 
Kesawan sulit parkir, ramai di siang hari, memiliki daya tarik visual, dan didukung dengan kebudayaan yang beragam, mengharapkan agar Kawasan Kesawan direvitalisasi.

Yang ke-empat perspektif pengembangan, citra Kawasan Kesawan di malam hari yang ramai dengan masyarakat namun identik sebagai Chinatown yang berbaur dengan keragaman budaya, oleh responden diharapkan adanya perbaikan infrastruktur di area Kawasan Kesawan. Terdapat tiga elemen penggerak pengembangan dalam suatu kota, yaitu: masyarakat (people) yang menempati kawasan dalam periode tertentu, pihak pemerintah (power) sebagai pemegang kewenangan untuk menentukan jenis pemanfaatan kawasan, dan pihak swasta ( $p r o f i t$ ) yang berperan dalam pembangunan. Oleh Budihardjo (1993) menjelaskan mengenai pentingnya melindungi warisan budaya dengan pendekatan terhadap masyarakat dan sejarah. Hal ini berkaitan dengan keseimbangan tuntutan dan kebutuhan agar upaya pelestarian dalam mendekati, mengimbau dan menyadarkan penentu kebijakan dan pihak swasta dapat berhasil.

Tabel 6. Harapan terhadap Kawasan Kesawan berdasarkan Citra

\begin{tabular}{ll|l|l}
\hline \multicolumn{2}{c}{ Citra } & Harapan & Perspektif \\
\hline 1 & $\begin{array}{l}\text { Kawasan Chinatown } \\
\text { Identitas }\end{array}$ & Identitas Chinatown & Konservasi \\
\hline 2 & $\begin{array}{l}\text { Seram } \\
\text { Daya Tarik Wisata }\end{array}$ & Icon Kota Medan & Pariwisata \\
\hline 3 & $\begin{array}{l}\text { Sulit Parkir } \\
\text { Daya Tarik Visual } \\
\text { Keramaian di Siang } \\
\text { Hari } \\
\text { Budaya }\end{array}$ & Revitalisasi & Revitalisasi \\
\hline 4 & $\begin{array}{l}\text { Keramaian Malam } \\
\text { Kawasan Chinatown } \\
\text { Budaya }\end{array}$ & Infrastruktur & Pengembangan \\
\hline (Sumber : Hasil Analisis. 2018) & & \\
\hline
\end{tabular}

\section{Simpulan}

Penelitian ini mengungkap 13 dimensi citra Kawasan Kesawan, yang berupa enam citra baik dan tujuh citra buruk. Enam citra baik Kawasan Kesawan yaitu kawasan konservasi, daya tarik wisata, identitas, budaya, daya tarik visual, dan kawasan Chinatown. Tujuh citra yang buruk Kawasan Kesawan, yaitu : seram, lingkungan kotor, jalur pedestrian buruk, keramaian siang, sulit parkir, keramaian malam, dan aksesibilitas sulit. Penelitian ini juga mengungkap sepuluh dimensi harapan terhadap Kawasan Kesawan, yaitu revitalisasi, infrastruktur, aksesibilitas, fasilitas, identitas Chinatown, konservasi, komodifikasi, perluasan, pembatasan akses, dan icon Kota Medan. Dari korelasi antara dimensi citra dan harapan ditemukan empat perspektif terhadap Kawasan Kesawan yaitu konservasi, pariwisata, revitalisasi, dan pengembangan. Empat perspektif ini mewakili citra dan harapan dari masyarakat Kota Medan. Karena itu empat perspektif ini dapat menjadi pijakan dalam penyusunan kebijakan terhadap Kawasan Kesawan.

Penelitian dilakukan dengan dua tahap kualitatif dan kuantitatif, serta penelitian mengungkap perspektif dari masyarakat Kota Medan sebagai salah satu stakeholder Kota Medan, merupakan kelebihan dari penelitian ini. Hasil penelitian perlu diverifikasi pada penelitian berikutnya untuk meningkatkan reliability hasil penelitian. 


\section{Ucapan Terima Kasih}

Terimakasih banyak kepada Bapak Hanson E. Kusuma yang telah banyak membantu dalam menyelesaikan penulisan karya ilmiah ini. Juga kepada rekan seperjuangan yang saling membantu dan mengingatkan dalam pemeriksaan karya tulis ilmiah ini Cahyo S. Hutomo. Semoga karya tulis ini dapat memberi manfaat dalam dunia akademik maupun memperkaya ilmu pengetahuan mengenai Kawasan Kesawan yang terkait dengan penelitian. Senang dapat belajar dan bekerja sama dengan kalian.

Terimakasih banyak atas bimbingan, saran dan kritik yang membangun dan mempercepat proses penulisan.

\section{Daftar Pustaka}

Bryant, F.B., \& Yarnold, P. R. 2001. Principal-Components Analysis and Exploratory and Confirmatory Factor Analysis In L. G. Grimm, \& P.R. Yarnold, Understanding Multivariate Statistics (pp. 99-136). Washington: American Psychological Association.

Creswell, J.W. 2006. Qualitative Inquiry and Research Design: Choosing Among Five Approaches. California: Sage Publication, Inc.

Fatimah, Nurlita Btari. 2017. Perencanaan Lanskap untuk Pelestarian Kawasan Sejarah Kesawan Medan. Bogor: Institut Pertanian Bogor.

Groat, L, \& Wang, D. 2002. Architectural Research Methods. New York: Jhon Wiley \& Sons, Inc.

Hadinugroho, Dwi. L., \& Eddy, Firman. (2016). Jelajah Tempat Berkarakter bagi Model Revitalisasi Pasar Petisah Medan. Prosiding Temu Ilmiah IPLBI, (B 021-B 026).

Hadinugroho, Dwi. L. 2017. Kajian Model Revitalisasi Kawasan Heritage Kawasan Kesawan Medan. Seminar Ikatan Lingkungan Binaan Indonesia (IPLBI), Vol.1 (B 045-052).

Hadinugroho, Dwi. L. 2018. Demolition: Tantangan Pelestarian Arsitektur Kawasan Kesawan Medan. Jurnal Arsitektur dan Perkotaan "KORIDOR”, Vol.9, No.2 (236-242).

Haryono, Azis Yon. 2015. Penanda Kawasan sebagai Penguat Nilai Filosofis Sumbu Utama Kota Yogyakarta. Jurnal Arsitektur “ATRIUM” Vol.1, No.2 (93-107).

Lubis, M. Dolok. 2004. Identitas Fungsi Ruko Kesawan. e-USU Repository.

Rachman, Maman. 2012. Konservasi Nilai dan Warisan Budaya. Indonesian Journal of Conservation, Vol.1, No.1 (30-39).

Rahardjo, Supratikno. 2013. Beberapa Permasalahan Pelestarian Kawasan Cagar Budaya dan Strategi Solusinya. Jurnal Konservasi Cagar Budaya Borobudur Vol.7, No.2 (4-17).

Pettricia, H.A., Wardhani, D.K., \& Antariksa. 2014. Elemen Pembentuk Citra Kawasan Bersejarah di Pusat Kota Malang. Jurnal RUAS Vol. 12, No.1 (10-23).

Purwantiasning, A.W., Mauliani, L., \& Aqli, W. 2012. Tipologi Konversi Bangunan Tua di Pusat Kota Studi Kasus Pecinan di Singapura dan Petak Sembilan di Jakarta. Jurnal Arsitektur NALARs, Vol.11, No.2 (181-198).

Tampubolon, M.V., Kusuma, H.E., \& Hutomo, C.S. 2019. Citra dan Harapan terhadap Kawasan Kesawan di Kota Medan. Jurnal Arsitektur NALARs, Vol.19, No.1 (59-68).

Tutuko, Pindo. 2010. Community Attachment pada Transformasi Desain Bangunan Permukiman di Sekitar Kawasan Pecinan. Local Wisdom Jurnal Ilmiah Online, Vol.2, No.4 (10-19). 